\title{
PRÁTICAS DOCENTES INOVADORAS: caminhando na incerteza momentânea entre o status quo e a ousadia
}

\author{
Sandra Maria Nascimento de Mattos \\ José Roberto Linhares de Mattos
}

\section{Resumo}

O presente artigo tem como objetivo apresentar práticas docentes inovadoras que transgridem o status quo como maneiras de propiciar o ensino remoto híbrido, favorecendo a aprendizagem e possibilitando nenhum estudante a menos nesse novo fazer aulas em época de pandemia. Essas práticas inovadoras envolvem o encontro cultural com suas variadas possibilidades para promover o ensino e a aprendizagem significativa dos estudantes. Na atual realidade brasileira, em que se acirram as distorções socioeconômicas e culturais, é urgente caminhar pela decolonialidade como aspecto para a insurgência, resistência e reexistência. $\mathrm{O}$ caminho teórico teve base nos estudos sobre práticas decoloniais de Mattos (2020a, 2020b), Mattos e Mattos (2019) e decolonialidade na visão de Walsh $(2013,2017)$, bem como o conceito de ensino remoto de Valente (2014) e Motin et al. (2020) e híbrido de Moran (2013) e Bacich e Moran (2015). A pesquisa está baseada em relatos de experiências que contribuem com a discussão sobre o ensino remoto híbrido, revelando enfrentamentos e dificuldades, coletados em memorial descritivo, elaborados por professores de diferentes áreas, no resgate das experiências com esse tipo de ensino. A conclusão direciona para práticas docentes decoloniais como um dos caminhos para modificar o status quo, ousando por práticas inovadoras emergenciais. Aponta, ainda, que nem todas as práticas pedagógicas desenvolvidas no ensino remoto híbrido são exitosas, mas são percursos de incerteza e de superação.

Palavras-chave: Práticas docentes inovadoras; ensino remoto híbrido; decolonialidade.

\section{INNOVATIVE TEACHING PRACTICES: walking in the momentary uncertainty between the status quo and daring}

\begin{abstract}
This article aims to present innovative teaching practices that violate the status quo as ways to provide hybrid remote education, favoring learning and enabling no less student in this new class to take classes in a time of pandemic. These innovative practices involve the cultural encounter with its varied possibilities to promote the teaching and meaningful learning of students. In the current Brazilian reality, in which socioeconomic and cultural distortions intensify, it is urgent to move towards decoloniality as an aspect for the insurgency, resistance and re-existence. The theoretical path was based on studies on decolonial practices by Mattos (2020a, 2020b), Mattos and Mattos (2019) and decoloniality in the view of Walsh (2013, 2017), as well as the concept of remote teaching by Valente (2014) and Motin et al. (2020) and hybrid by Moran (2013) and Bacich and Moran (2015). The research is based on reports of experiences that contribute to the discussion on hybrid remote education, revealing confrontations and difficulties, collected in a descriptive memorial, prepared by teachers from different areas, in the rescue of experiences with this type of teaching. The conclusion points to decolonial teaching practices as one of the ways to modify the status quo, daring for innovative emergency practices. It also points out that not all pedagogical practices developed in hybrid remote education are successful, but they are paths of uncertainty and overcoming.
\end{abstract}

Keywords: Innovative teaching practices; hybrid remote education; decoloniality. 


\title{
PRÁCTICAS DE ENSEÑANZA INNOVADORAS:
}

\author{
caminando en la incertidumbre momentánea entre el status quo y la osadía
}

Resumen

Este artículo tiene como objetivo presentar las prácticas de enseñanza innovadoras que violan el status quo como formas de brindar educación híbrida remota, favoreciendo el aprendizaje y permitiendo que no menos estudiantes de esta nueva clase tomen clases en tiempos de pandemia. Estas prácticas innovadoras involucran el encuentro cultural con sus variadas posibilidades para promover la enseñanza y el aprendizaje significativo de los estudiantes. En la realidad brasileña actual, en la que se intensifican las distorsiones socioeconómicas y culturales, es urgente avanzar hacia la decolonialidad como aspecto de la insurgencia, la resistencia y la reexistencia. El camino teórico se basó en los estudios sobre las prácticas decoloniales de Mattos (2020a, 2020b), Mattos y Mattos (2019) y la decolonialidad en la mirada de Walsh (2013, 2017), así como el concepto de enseñanza a distancia de Valente (2014) y Motin. et al. (2020) e híbrido de Moran (2013) y Bacich y Moran (2015). La investigación se basa en relatos de experiencias que contribuyen a la discusión sobre educación remota híbrida, revelando enfrentamientos y dificultades, recogidos en un memorial descriptivo, elaborado por docentes desde diferentes áreas, en el rescate de experiencias con este tipo de enseñanza. La conclusión apunta a las prácticas docentes decoloniales como una de las formas de modificar el status quo, atreviéndose con prácticas innovadoras de emergencia. También señala que no todas las prácticas pedagógicas desarrolladas en educación remota híbrida tienen éxito, pero son caminos de incertidumbre y superación.

Palabras clave: Prácticas de enseñanza innovadoras; educación remota híbrida; decolonialidad.

\section{INTRODUÇÃO}

\author{
Se houver caminho, estaremos lá. \\ Se não houver caminho, \\ abriremos, em luta, novos rumos, \\ pontes entre a denúncia e o anúncio, \\ necessários por cá. \\ Burburinhos que adivinho, \\ percursos, forjando vidas em resumos. \\ Algo que já éprenúncio, \\ talvez, de dias melhores, \\ que não apagam os piores, \\ mas com certeza cria elos afetivos, \\ reativos, coletivos, efetivos. \\ Sandra Mattos, primavera de 2020.
}

Estamos vivendo momentos de incertezas que nos levam a percorrer caminhos poucos trilhados. A crise que abalou o mundo, resvalando intensamente no Brasil, apresentou-nos rumos nunca dantes navegados e nos fez transitar entre o possível e o impossível. Esgueiramo-nos por entre-lugares (BHABHA, 1998) como espaços que reinventam os subjugados por intermédio da geração e difusão de conhecimentos, contendo vozes que anunciam e enunciam o pensamento que somente eles podem desvendar. A intolerância e falta de empatia, por parte dos governos, apresentou-nos um lado cruel e, muitas vezes surreal, sobre relegar, aos considerados desvalidos, o descaso, a invisibilidade e aumentar a distorção sociocultural e econômica tão marcantes em terras brasilis. 
Com as escolas fechadas e todos os estudantes sem aula, foi necessário buscar possibilidades para que continuassem suas aprendizagens. Os professores, momentaneamente, sentiram-se deslocados, desamparados e impotentes. Entretanto, reinventar-nos é um componente que está presente em nossa bagagem profissional. A luta constante, a visão à frente e o compromisso para com os estudantes fizeram com que muitos professores assumissem um caminhar repleto de incertezas, modificação de posição e, muitas vezes, reviravolta de práticas, que da noite para o dia, perderam todas as suas características ditas comuns e cotidianas, para se apresentarem como um ambiente virtual de aprendizagem.

As dificuldades enfrentadas por professores de escolas públicas acirram, ainda mais, a importância de ensinar. A maneira como ensinar, o acréscimo e acúmulo de atividades diárias, a necessidade de manter os estudantes ativos e aprendendo, impulsionam estes professores a desenvolverem práticas docentes decoloniais (MATTOS, 2020a). Cabe ressaltar que entendemos práticas docentes decoloniais como aquelas que buscam a justiça social com equidade de oportunidades e intervêm para que os estudantes desejem aprender e desenvolvam uma aprendizagem significativa (AUSUBEL, 2000) com a intenção de transcender aos aspectos da colonialidade impostos pela cultura hegemônica e opressora.

A encruzilhada que nos é posta, dá oportunidades para caminharmos entre o caos imposto por governantes e políticas públicas, bem como compreender a visão de múltiplos percursos de ensino e de aprendizagem. Caminhar no fio da navalha, enquanto docentes, em épocas as quais a cultura do ódio impera, volve nossos olhares para uma leitura de mundo mais profunda, profícua e criteriosa. Auxiliar nossos estudantes a volver seus olhos é estratégia essencial para, ao ler o mundo, consigam reestruturar, pelo menos, a comunidade em que vivem. Caminhar à margem não é destino, destino é desenvolver processos de recontextualização (CONTRERAS DOMINGO, 1994) e de decolonização como aspecto para a insurgência, a resistência e reexistir (WALSH, 2017), tomando como suportes o pensamento crítico, o raciocínio político, sociocultural e existencial.

\section{AULAS REMOTAS HÍBRIDAS: TRANSITANDO ENTRE O PRESENCIAL E O VIRTUAL}

Uma aula é considerada toda maneira de possibilitar o ensino para alguém e a aprendizagem de alguém sobre algum conteúdo de uma disciplina. Essa aula deve dar oportunidade para o desenvolvimento cognitivo, processual e afetivo das pessoas nela envolvidas. As rotinas - não tidas aqui como algo mecânico, mas como um itinerário - estabelecidas em uma aula atuam como vivências e experiências de trajetórias escolares, das quais as atividades do professor são realizadas por processos de ações que possam levar à aprendizagem dos alunos. Ao planejar uma seção de aula - estamos considerando seção de aula toda trajetória desenvolvida em sala de aula para ensinar um conteúdo -, o professor cria trilhas de ensino e de aprendizagem com as quais os estudantes desbravam o saber-fazer pelo diálogo, pela troca e pela colaboração.

O mais intrigante é que em uma seção de aula existem diferentes caminhos com os quais podemos ensinar um conteúdo a alguém. Nossas escolhas partem daquilo que entendemos ser viável aos nossos estudantes, considerando que todos têm capacidades para aprender, a partir do momento em que eles desejem aprender. Não queremos entrar pelo mérito da motivação, mas em trajetórias para diminuir ou reverter "[...] o estranhamento habitual que envolve os conceitos matemáticos escolares, desenvolvendo o desejo em aprender, criando oportunidades para que o mesmo aconteça" (MATTOS, 2020a, p. 152). É importante lembrar que cada seção de aula deve 
partir daquilo que o estudante já sabe, tomar aspectos da cultura para contextualizar os conceitos matemáticos escolares e, sempre que possível, trabalhar interdisciplinarmente.

A partir do terceiro mês de 2020, com a pandemia do novo coronavírus, ocorreram transformações na maneira de fazer aulas. $\mathrm{O}$ ato de ensinar e de aprender foram atingidos com interrupções abruptas, ocasionadas pela falta de perspectivas iniciais, pois priorizar a vida é essencial. Com isso, é restituída a questão da escola enquanto espaço social, a sua especificidade e, ao mesmo tempo, a do professor. A escola tida como um espaço retrógado, desmotivante e alienante, mas que precisa urgentemente ser reformulada para atender ao atual estado de emergência que se instalou no país. Quanto aos professores a questão recai sobre a formação a eles destinada. Conjuntamente a isso, esses professores tiveram que engavetar tudo que sabiam e criar caminhos de ensino e de aprendizagem, sem quaisquer auxílios institucionais ou governamentais.

Para sanar tal lacuna foi tomada como medida o ensino remoto, baseado na lei de diretrizes e bases da educação nacional - LDBEN 9394/96 (BRASIL, 1996) que em seu artigo 80 possibilita o ensino a distância, ensino esse que foi transladado para o remoto. Nessa lógica, o ensino remoto surge como uma saída emergencial para um momento de extrema incerteza, destinado a amenizar os impactos catastróficos mantidos pelo isolamento social dessa pandemia. O ensino remoto, diferentemente do ensino à distância, preconiza a transmissão de todas as aulas síncronas, ou seja, em tempo real. A intenção de aulas síncronas é manter a rotina de sala de aula em ambiente virtual.

De acordo com Motin et al. (2020, p. 248) "a proposta é que professor e estudantes de uma turma tenham interações nos mesmos horários em que as aulas da disciplina ocorriam no modelo presencial". Como se fosse possível! Grosso modo, significa adequar a apresentação dos conteúdos escolares, mas seguindo o que foi planejado para o ensino presencial. Com a mesma lógica presencial, os estudantes têm oportunidades de sanarem suas dúvidas e o professor de respondêlos imediatamente. Ainda, segundo Motin et al. (2020, p. 249) "com esta dinâmica é possível ser mantida a rotina de sala de aula em um ambiente virtual acessado por cada um, em diferentes localidades", estreitando-se as distâncias espaço-tempo entre professor e os estudantes.

Diante dessa lógica, o que ficou subentendido é que seria facilitado a utilização das tecnologias e de seus recursos digitais, já que a comunicação e a interação seriam desenvolvidas em recursos já conhecidos, tanto dos professores quanto dos estudantes, como é o caso do Skype, Google Hangout ou mesmo pelo WhatsApp. Entretanto novos recursos foram criados como maneira de melhorar a comunicação entre professores e estudantes em tempo real, como é o caso do Google Classroom, Google Meet, Zoom e Teams da Microsoft, ampliando as possibilidades da aula. O diferencial desses novos recursos é permitir a gravação da seção de aula, facilitando aos estudantes reverem as aulas e dando acesso para aqueles que não possam ver ou não tenham possibilidades de ver no momento real.

É fato que a transição do ensino presencial para o remoto não é algo cômodo, tampouco impossível. É fato, também, que o ensino exige atividades e momentos práticos que devem ser relacionados às experiencias e vivências dos estudantes, tal qual, para que a aprendizagem ganhe sentido e seja significativa. Entendemos que a aprendizagem significativa "[...] se torna eficaz quando o aluno é afetado e percebe que os saberes e fazeres existentes em sua cultura são tidos como suportes para o ensino dos conceitos matemáticos escolares" (MATTOS; MATTOS, 2019, p. 103). Assim sendo, na aula remota quem ganha destaque são os estudantes e o professor passa a ser o mediador dos diferentes tipos de conhecimento.

O ensino remoto expandiu as tarefas dos professores e, ao mesmo tempo, inviabilizou a participação de muitos estudantes, que ficaram à margem do processo digital, por motivos óbvios, 
tais como não terem recursos tecnológicos ou internet. É lógico que a discrepância entre os estudantes de instituições públicas fica mais evidente pelo afastamento socioeconômico e cultural. Essa discrepância amplia a crise da desigualdade socioeconômica no Brasil, segregando ainda mais os grupos inferiorizados. Entretanto, os professores, que não querem deixar algum estudante a margem, criam materiais impressos para que estes tenham as mesmas oportunidades dos outros. Vale ressaltar que o professor se volta para a individualização, diferenciação e personalização do ensino e da aprendizagem para que mais estudantes sejam favorecidos com as tarefas e estratégias utilizadas em uma seção de aula.

O ensino remoto torna-se híbrido, combinando vários espaços, tempos, materiais, metodologias, estratégias, atividades, tarefas e as pessoas nele envolvidas. Tomamos por híbrido, o ensino que em essência mistura ou combina processos organizados com processos abertos de ensino e aprendizagem. Para Moran (2013, p. 28) "o ensino é híbrido porque todos somos aprendizes e mestres, consumidores e produtores de informação e de conhecimento". Ainda, de acordo com Bacich e Moran (2015, p. 45) o ensino híbrido parte "do pressuposto de que não há uma única forma de aprender e, por consequência, não há uma única forma de ensinar. Existem diferentes maneiras de aprender e ensinar". Consequentemente, no ensino remoto híbrido há a confluência de variados suportes, tanto presenciais quanto virtuais, que favorecem o ensinar e o aprender.

Para Valente (2014, p. 85) "a combinação do que ocorre on-line com o que ocorre em sala de aula presencialmente pode ser muito rica e beneficiar a aprendizagem dos alunos sob todos os aspectos". É um momento de mudança, de saída do confortável e de exploração das possibilidades estabelecidas pela disseminação do uso de tecnologias. Entretanto, muitos professores sentem-se inseguros e até abandonados, principalmente por não terem certeza de que os estudantes estão participando e aprendendo. Apesar do esforço implementado para sanar o desinteresse dos estudantes, há certa cautela em propor algo inovador, até porque o ensino remoto híbrido impacta consideravelmente todos os envolvidos. Por esse ângulo, os professores preferem transitar pelas estratégias do ensino presencial com pequenas alterações.

\section{PRÁTICAS PEDAGÓGICAS INOVADORAS: VIAJANDO ENTRE AS TIC E AS METODOLOGIAS ATIVAS}

Optamos por começar este tópico esclarecendo alguns conceitos essenciais para o entendimento daquilo que recorremos como parte de nosso aporte teórico. Assim sendo, iniciamos abordando o conceito inovação, tão estudado e tão complexo. Não é de agora que esse conceito é utilizado, mas atualmente o conceito inovação explodiu devido a utilização do ensino remoto híbrido. Inovação está associada à criatividade, assim como à mudança, principalmente quando se trata da utilização das TIC como recurso de fazer aulas. Nessa lógica, inovar é um momento de mudança criativa. Não entraremos no mérito histórico do termo, somente trazer o essencial.

No século passado, desde a década de 1970, o termo inovação - associado ao mundo econômico, administrativo e de produção -, alavanca o campo educacional com expectativas de melhoria para as práticas pedagógicas inovadoras. Messina (2001, p. 226) afirma que “[...] inovação é algo aberto, capaz de adotar múltiplas formas e significados, associados com o contexto no qual se insere". A autora destaca que inovar é um meio para transformar os sistemas educacionais, já que sendo um processo multidimensional transforma o espaço e as próprias pessoas. Nos tempos atuais, em que a pandemia do novo coronavírus impactou ainda mais as crises socioeconômica e 
política, é acentuada a exclusão dos menos favorecidos, os quais já resistem aos processos educacionais diferenciados, logo, é oportuno tratar a inovação como um momento de mudança criativa.

Entendemos que as práticas pedagógicas inovadoras devem romper com o modelo bancário de ensino, constituindo-se aliadas às TIC e às metodologias ativas como um percurso de mudança criativa. Consequentemente, essas práticas são assumidas como um processo que transgridem o instituído nas instituições de ensino. Ressaltamos que são ações individuais ou coletivas para lutar contra as discriminações sociais, políticas e culturais. Tratar de práticas pedagógicas inovadoras é valorizar a constituição de estratégias decoloniais de ensino que visam a insubordinação criativa (D’AMBROSIO; LOPES, 2015), causando ruptura no status quo para garantir ações equitativas, as quais têm a intenção de diminuir ou extirpar as desigualdades socioculturais.

Cabe, ainda, estabelecer nosso entendimento sobre o conceito decolonialidade. Tomamos o conceito de decolonialidade como no trabalho de Walsh (2013). A autora afirma que "lo decolonial denota, entonces, un camino de lucha continuo en el cual se puede identificar, visibilizar y alentar 'lugares' de exterioridad y construcciones alter-(n)ativas" (WALSH, 2013, p. 25, nota 2). Dessa maneira, o giro decolonial se faz pela abertura e liberdade outras de distanciar-se das variadas formas de colonialidade. Ainda, de acordo com Walsh (2013, p. 506):

La pedagogía de la felicidad sólo es posible para los que deciden construir una "educación para la vida". Esta educación incluye varios giros paradigmáticos, que corresponden al ejercicio de la innovación de la innovación, o sea, realizar giros cualitativos en la forma de innovar, iniciando una jornada epistemológica con implicaciones ontológicas, metodológicas y axiológicas [...].

O que corrobora nosso entendimento de inovação. Isto posto, entendemos decolonialidade como uma maneira de transcender ao que está instituído pelo Estado e pelas instituições como expressão de colonialidade de poder, do saber e do ser. Essa visão permite-nos olhar a decolonialidade como um percurso em que as práticas docentes são de oposição, resistência, insurgência e intervenção ao status quo, bem como, àquilo que diz respeito a produção de conhecimento como anúncio e denúncia da colonialidade de saber. Diante disso, é oportuno denunciar a ocorrência de um "epistemicídio" (SANTOS; MENESES, 2009, p. 10) sociocultural, desperdiçando a riqueza das experiências cognitivas, ou seja, ações que destruindo o conhecimento dos grupos socioculturais considerados subalternos e marginalizados, destroem os seres humanos que formam esses grupos.

Devemos, também, pontuar o que chamamos de práticas docentes decoloniais (MATTOS, 2020a). Para incorporar tais práticas é necessário conhecer os estudantes, sua realidade, suas vivências e experiências, tal qual aquilo que ele já sabe. Além disso, a prática docente decolonial tomada como característica social é vista como um caminho de insurgência, resistência e conscientização crítica a respeito dos diferentes tipos de colonialidade que estamos envolvidos. Portanto, a prática docente decolonial move-se pela mistura dos saberes disciplinares, curriculares, didáticos, experienciais ou profissionais com a cultura da qual os estudantes fazem parte e da qual se apropriam dos saberes e fazeres inerentes à mesma. Por conseguinte, aderir a práticas docentes decoloniais envolve conscientizar para politizar.

Entendendo práticas docentes decoloniais com essas características, construímo-la a partir da temática que abrange os conteúdos de nossa área e que faz parte do nosso objeto de ensino, favorecendo a prática cognoscitiva dos nossos estudantes e revelando a ideologia imposta pelos 
currículos e materiais didáticos. Dessa maneira, temos que falar com os estudantes, o que corrobora Freire (2003, p. 113, grifos do autor) quando afirma que "[...] é escutando que aprendemos a falar com eles. Somente quem escuta paciente e criticamente o outro, fala com ele, mesmo que, em certas condições, precisa falar a ele". Ao praticar o falar com, recorremos a Barbier (1998) que traz o conceito de escuta sensível aproximando-se de uma relação poético-existencial que conta com o imprevisível e investe no outro.

Usufruímos da escuta sensível como um caminho para tomar consciência e reestruturar estrategicamente práticas pedagógicas inovadoras como ações de mudança criativa. Mattos (2020b, p. 249) afirma que "a escuta sensível nos traz para a afetividade, para a amorosidade [...]" e buscando Freire (2003) afirma que agindo amorosamente o professor tem condições de lutar politicamente. No momento atual, mais do nunca, é essencial desvelar o lado ideológico e político que se esgueiram nos materiais e livros didáticos disponibilizados aos estudantes. Entendendo o currículo escolar como parte da cultura, isto é, parte dos conhecimentos gerados e difundidos pelos grupos socioculturais em um dado momento histórico, não nos é permitido comunicar os conceitos matemáticos escolares e hegemônicos como os únicos capazes de auxiliar os estudantes na atual realidade.

O primeiro recurso para o ensino remoto é a videoaula. Entretanto, não da mesma maneira que no ensino à distância, visto que as aulas são gravadas no percurso de aula. Sendo assim, a videoaula no ensino remoto híbrido combina a explanação do professor com uma apresentação em PowerPoint. Os benefícios desse tipo de aula é promover o mesmo entrosamento existente na aula presencial, permitindo a partir da interatividade sanar as dúvidas momentâneas. Para além disso, traz a sensação de realidade vivida que proporciona maior interesse e favorece a aprendizagem diferenciada. Cabe ressaltar que as videoaulas podem ser acessadas por diferentes aparelhos como celulares, computadores e notebook, o que pode facilitar a participação dos estudantes na aula. Além disso, após a gravação da aula e sua disponibilização, ela serve para rever o conteúdo exposto afim de sanar dúvidas ainda existentes.

O tipo de comunicação nas videoaulas necessita falar com os estudantes, utilizando uma linguagem adequada e acessível aos estudantes, da mesma maneira que seria realizada em uma aula presencial. Ao planejar uma videoaula o docente opta por segmentar os conceitos a serem explicados, facilitando o debate e buscando a interação constante dos estudantes. É preciso ousar e buscar novas maneiras de fazer aulas, pois não se pode fazer aulas de baixa qualidade devido ao novo normal, tampouco mitigar o conhecimento para os estudantes, o que seria um risco ainda maior para aqueles menos favorecidos. Nessa ótica, a videoaula se faz como uma modalidade expositiva e sistemática, favorecendo o acompanhamento do desenvolvimento dos conteúdos escolares expostos.

Sabemos que a videoaula é um recurso eficaz e que, didaticamente, assume a função informativa. Ademais, pode-se utilizar outros recursos digitais em uma videoaula, tais como, documentários, entrevistas, vídeos, entre outros que auxiliam a aquisição do conhecimento por parte dos estudantes. Pode-se, ainda, trabalhar colaborativamente para a reconstrução dos conhecimentos ensinados com utilização de brainstorming que facilita o processo criativo dos estudantes na liberação das ideias. Para isso, o professor lança mão de uma lousa virtual onde cada um, individual ou coletivamente colocam suas ideias e reelaboram o conteúdo aprendido. Temos que destacar que o material impresso é parte importante desse processo e, por isso, o que é produzido, é impresso e distribuído a todos. 
Outra atividade utilizada é uma metodologia ativa chamada sala de aula invertida ou flipped classroom. Segundo Valente (2014) não é uma proposta nova, utilizada pela primeira vez 1996 nos Estados Unidos. A aula invertida funciona como um reforço escolar, isto é, após o professor fazer sua aula e gravá-la, os estudantes vão estudar o material transmitido e realizar alguma atividade de avaliação. É um caminho para o professor ter a nítida noção sobre a aprendizagem do estudante. Valente $(2014$, p. 86) afirma que "na abordagem da sala de aula invertida, o aluno estuda antes da aula e a aula se torna o lugar de aprendizagem ativa, onde há perguntas, discussões e atividades práticas". A modificação ocorrida na metodologia foi transpor o estudo para posterior, mas que é utilizado na aula seguinte para sanar as possíveis dificuldades encontradas pelos estudantes ao realizar a tarefa avaliativa.

Diante do exposto, adentramos o ensino remoto híbrido impulsionados pela busca de novas maneiras de fazer aulas. Impõe-se um novo olhar para a sala de aula que neste momento tornou-se nossa casa, o quadro passou a ser a tela do computador, os métodos, os mais diversificados recursos da comunicação virtual e os materiais, os diferentes aportes do ambiente virtual de aprendizagem. Aliado a tudo isso, nos deparamos com estudantes segregados do compartilhamento dessas aulas inovadoras pelos motivos citados anteriormente. Entretanto, o esforço é nenhum estudante a menos, todos individual ou coletivamente atuando colaborativamente para alcançar o ensino e promover a aprendizagem de todos.

\section{PRÁTICAS DOCENTES INOVADORAS: CAMINHOS ENTRE A INCERTEZA E A OUSADIA}

Devemos esclarecer que uma pesquisa com seu percurso iniciado, que no meio do caminho teve que ser modificada, por nos deparamos com uma pandemia sem precedentes, já caracteriza um ato de incerteza. Tivemos que modificar trajetórias, nos adaptarmos, atos que caracterizam ousadia e resistência. Assim sendo, uma das opções foi utilizar como instrumento o memorial para a coleta de dados, devido ao isolamento social. Inicialmente seria realizada roda de conversa com professores de diferentes áreas. Afirmamos que nosso propósito era buscar informações sobre as experiências exitosas do fazer aulas, trazendo algumas dessas práticas para a discussão.

Como fomos pegos de sobressalto, também alteramos nosso objetivo. O foco continuou o mesmo que são as práticas docentes, mas o objetivo passou por reajustes, e foi estabelecido como objetivo apresentar práticas docentes inovadoras que transgridem o status quo como maneiras de propiciar o ensino remoto híbrido, favorecendo a aprendizagem e possibilitando nenhum estudante a menos nesse novo fazer aulas em época de pandemia. Ressaltamos, ainda, que os memoriais foram enviados via e-mail ou WhatsApp.

Esclarecido isso, trazemos alguns relatos contidos nos memoriais de alguns professores de diferentes áreas de conhecimento. É importante considerar que os professores tiveram que rever caminhos para o ano letivo de 2020, há pouco iniciado. Como nos relata uma das professoras "estávamos começando a ajustar aulas e trabalhos com os alunos. Começamos o preenchimento dos diários e de repente o governo mandou suspender as aulas presenciais" (Professora de artes, 2020). A surpresa e incerteza partiu do não entendimento de como seriam as aulas nessa nova realidade. Em relato uma das professoras afirma que tanto a equipe gestora quanto a pedagógica "orientaram e repassaram instruções aos estudantes e professores, pois não se tratava de um recesso ou férias, mas sim de medidas de cuidado e prevenção" (Professora de biologia, 2020). Os professores ficaram um tempo sem esclarecimentos, passaram por momentos de angústias a 
respeito dos conteúdos escolares e sobre os próprios estudantes. Nesse ínterim descortinou-se como opção o ensino remoto híbrido.

Foi um momento difícil, alguns professores não sabiam como lidar com os recursos para o ensino remoto. A professora de artes relata: "tive que adaptar minhas aulas de arte, uma disciplina que trabalha com a prática manual, em que grande parte dos alunos tem dificuldades para acessarem a internet" (Professora de artes, 2020). Começava assim, outra angústia para esses educadores. Tinham que pensar como não permitir que algum estudante ficasse de fora, apesar de ter que manter vínculo com os estudantes por meio das redes sociais. Uma professora relata que essa comunicação era uma maneira de "havendo novas informações e orientações, os mesmos seriam informados, através dos recursos de mídias e outros meios de comunicação" (Professora de biologia, 2020). Com o ensino remoto híbrido novas oportunidades surgiram e novas incertezas também. Os professores tiveram que, além de fazer suas aulas, minimizar as dificuldades encontradas por alguns estudantes, tanto de ausência de recursos quanto nos aspectos cognitivos e afetivos.

Uma das professoras afirma que: "temos que nos adequar com o momento que estamos vivenciando, pois isto não é motivo que impeça o bom desenvolvimento do conhecimento, independentemente como serão transmitidas as aulas" (Professora de matemática, 2020). Segundo essa professora, o mais importante é como apresentar o conteúdo para que os estudantes aprendam significativamente, nos reportando a Ausubel (2000) sobre a maneira de apresentar um material potencialmente significativo que favoreça a aprendizagem significativa. De acordo com essa lógica, um professor relata que "dentre tantos desafios que tenho enfrentado como professor ao longo dessa caminhada pandêmica, no final de cada dia ao analisar o percurso percebo avanço" (Professor de matemática, 2020). Segundo esse professor, os caminhos de incertezas percorridos, inicialmente, trouxeram esperança.

A lei 14.040 de 18 de agosto de 2020 (BRASIL, 2020) estabelece normas educacionais excepcionais a serem adotadas durante o estado de calamidade pública vivenciado pela pandemia do novo coronavírus. No art. $3^{\circ}$, parágrafo $1^{\circ}$, é instituída as atividades pedagógicas não presenciais - APNP vinculadas aos conteúdos curriculares. Mediante o estabelecido na lei, entendemos APNP como um conjunto de atividades a serem realizadas pelos professores, com ou sem mediação tecnológica, que garanta o atendimento acadêmico durante o período de restrições mantidos pela pandemia. Essas APNP visam promover o vínculo entre professores e estudantes, minimizando os impactos vivenciados por ambos, com o rompimento de aprendizagem presencial, na tentativa de colaborar com a permanência e êxito dos estudantes.

Diante disso, as instituições de ensino desenvolveram, junto com os docentes, variadas APNP. Alguns professores nos relataram sobre sua experiência como esse movimento de preparo dessas atividades. Para um dos professores: "atualmente ao analisar os resultados das Atividades Pedagógicas não Presenciais (APNP), presenciar os esforços e apoio das famílias, vejo que aquela caminhada incerta no início tem se tornado muito mais forte e confiante na atualidade" (Professor de matemática, 2020). Na unanimidade dos relatos há o consenso que eles tiveram que inovar, superar-se e insurgir para resistir aos impactos causados pela pandemia. Outras unanimidades foram: o envolvimento da família e os obstáculos enfrentados por alguns estudantes, pela ausência de recursos tecnológicos e de internet. Uma das professoras relata:

[...] muitos obstáculos surgiram nos primeiros momentos com tecnologia latente e principalmente pelas limitações de acesso à tecnologia de difícil acesso para os alunos da periferia em relação a comunicação através da internet e em relação a 
diferença entre as classes sociais que é vivenciada na região, cuja renda é de um salário mínimo, pois para driblar esses obstáculos foi necessário fazer uma interação no modelo de aprendizagem onde todos da família foram envolvidos a participarem das aulas e nas atividades possibilitando o interesse e qualidade no ensino (Professora de matemática, 2020).

Uma das opções, para sanar a ausência de recursos tecnológicos e de internet, foi a produção de material impresso a ser disponibilizado aos estudantes. Acrescentou-se para o professor uma produção de material que, além de conter a aula, tinha que dar conta de trazer muito bem esclarecido o conteúdo - aspecto esse que no ensino presencial ocorre naturalmente em uma aula expositiva - contido em cada material impresso. Além de transformar-se em youtuber, o professor passou a ser também designer de material impresso. Acrescenta-se a isso, algumas incertezas quanto ao aprendizado dos estudantes e a transposição da aula presencial para o ensino remoto, bem como, trazer a linguagem oral em linguagem escrita. Uma das professoras relatou:

Seguindo o planejamento de artes, desenvolvi atividades que envolviam arteterapia, artesanato, fotografia, reciclagem, produção de cartões solidários em forma de bandeirinhas juninas, origami, mosaico, pintura com produtos naturais, escultura de jornal e revista, animação com massinha de modelar, narração de histórias, teatro de sombras, enfim a minha maneira de desenvolver as aulas não mudou, o que na verdade mudou foi a utilização do trabalho remoto (Professora de artes, 2020).

Como podemos constatar nesse relato, a professora além de se responsabilizar com o conteúdo a ser explorado em sua disciplina, também estava comprometida em manter a relação afetiva com os estudantes, por isso, resolveu utilizar a arteterapia que é uma saída para utilizar a linguagem artística como base da comunicação, é óbvio sem o enfoque clínico, mas como recurso de estreitar o convívio virtual. Outra professora também traz a necessidade da interação afetiva com os estudantes. Segundo a professora é um desafio "sentir falta do contato com seus estudantes e da rotina das atividades desenvolvidas em sala de aula; de explicar os conteúdos, esclarecer dúvidas e outras formas de interação com os estudantes" (Professora de biologia, 2020). O que percebemos é que a dimensão afetiva eclodiu com o ensino remoto híbrido. Em Mattos (2020a), vemos que promover a felicidade é favorecer o ensino crítico e a aprendizagem prazerosa e libertadora, por meio de estratégias didáticopedagógicas instigantes, que minimizam fronteiras entre o cognitivo e o afetivo.

Obviamente, notamos que a imposição do ensino remoto e da utilização das APNP, por parte do governo, somam-se às estratégias de políticas públicas para controlar aquilo a ser ensinado aos estudantes, sem ao menos compreender as lacunas existentes, já que aulas remotas necessitam recursos tecnológicos e seus aparatos. Quanto aos docentes, provocados pelas imposições, conseguiram inovar, entendendo às reais necessidades dos estudantes. Muitos deles, foram às residências dos estudantes para que tivessem acesso, pelo menos, às APNP. Nessa lógica, concordamos com Walsh (2013, p. 507) quando afirma que

[...] los sistemas de educación, comunicación, cooperación e innovación "para el desarrollo" continúan su abominable misión de reproducir el más grave crimen occidental: el lavado de cerebro de las nuevas generaciones para que éstas acepten que la meta de su sociedad es "ser — una sociedad capitalista— desarrollada", y se olviden del derecho de todos los pueblos a una "vida plena y feliz en la diferencia". 
Portanto, os professores devem mudar suas posturas e iniciar um caminho para insurgir, já que a insurgência requer compromisso e um novo olhar para a realidade da qual os estudantes são membros, fazendo aulas nas quais os alunos se vejam representados, se tornem criativos e mais felizes. Precisam, a partir dessas práticas inovadoras, buscarem práticas decoloniais que confrontem as ações impostas pelo sistema governamental.

\section{CONSIDERAÇÕES FINAIS}

É uma constante, nessa época de pandemia, a necessidade do trabalho conjunto entre escola e família. Os professores relataram que foi uma das maneiras de aproximar os estudantes das aulas remotas. Constatamos que os professores e professoras que participaram da pesquisa buscaram de alguma maneira inovar e despertar o interesse dos estudantes. O stress e o cansaço aumentaram, mas muitos afirmam ser gratificante a superação a qual estão vivendo. Isso é verificado nos seguintes relatos: "uma realidade gratificante, pois tenho recebido mensagens de pais e alunos, agradecendo pelas atividades" (Professora de artes, 2020); "diante de uma 'realidade educacional incerta' e os resultados alcançado juntos aos alunos com a fiel parceria das famílias me sinto mais confiante a cada dia" (Professor de matemática, 2020); "o desafio continua, pois, os processos de ensino e aprendizagem exigem metodologias e critérios diferentes diante das dificuldades impostas pela pandemia" (Professora de biologia, 2020).

Acreditamos que as práticas docentes desenvolvidas no ensino remoto híbrido são inovadoras e, ao mesmo tempo, insurgentes. Iniciar mudanças, em meio ao caos imposto pela pandemia do novo coronavírus, já justifica a insurgência dessas práticas, ainda mais, quando essa mudança se faz criativamente. Esses professores ressurgiram e insurgiram, transgredindo a realidade e ultrapassando as barreiras que, algumas vezes, se impuseram nesse percurso emergencial. Vemos o compromisso para com a aprendizagem dos estudantes, cada qual em sua área, mas todos visaram a qualidade tanto das videoaulas gravadas quanto das remotas. Quanto aos materiais disponibilizados, os professores superaram-se e favoreceram a aprendizagem significativa dos estudantes, entrelaçando experiências e vivências.

Utilizar recursos como google meet, zoom, google classroom, entre outros, já anuncia as possibilidades que esses professores têm para inovar criativamente. Há nas entrelinhas dessas práticas docentes a denúncia de uma distorção socioeconômica ainda mais acirrada com a pandemia, deixando para eles a necessidade de sanar as dificuldades ocorridas por seus estudantes. Foi notório que todos os professores que participaram da pesquisa, nos momentos de aflição, conseguiram transgredir ao status quo impetrado por uma sociedade que é permeada por diferentes tipos de colonialidade. As práticas docentes apresentadas constituem um pequeno recorte de uma pesquisa com inúmeros professores que buscam fazer de suas aulas algo agradável para os estudantes. Essas aulas possibilitam um olhar crítico e reflexivo sobre aquilo que disponibilizamos aos nossos alunos, traduzidas como um descortinar de possibilidades, mescladas pelo diálogo, pela troca e pelas inter-relações estabelecidas entre a escola e a família.

Finalizamos esse texto com a certeza de que esses professores não serão os mesmos após a pandemia, tampouco vão querer sê-lo. É certo, também, a necessidade de conscientizar os estudantes sobre as discrepâncias socioeconômicas e culturais, sobre as quais eles devem reagir e ressignificar seu aprendizado. Ficou evidenciado o compromisso e a responsabilidade que os docentes assumiram, sobrevivendo a um ensino remoto emergencial, sem os devidos subsídios das esferas governamentais. O apoio veio da própria equipe das instituições escolares e da família, 
todos unidos para que a aprendizagem fosse agradável e significativa para todos os estudantes, já que a proposta era nenhum estudante a menos. 


\section{REFERÊNCIAS}

AUSUBEL, David P. Aquisição e retenção de conhecimentos: uma perspectiva cognitiva. Trad. Ligia Teopisto. Lisboa: Edições Técnicas, 2000.

BACICH, Lilian; MORAN, José. Aprender e ensinar com foco na educação híbrida. Revista Pátio, n. 25, p. 45-47, 2015. Disponível em: http://www2.eca.usp.br/moran/wpcontent/uploads/2015/07/hibrida.pdf. Acesso em 16 out. 2020.

BARBIER, René. A escuta sensível na abordagem transversal. In: BARBOSA, Joaquim G. (org.). Multirreferencialidade nas Ciências e na Educação. São Carlos: Editora da UFSCar, 1998. p.168-199.

BHABHA, Homi K. O local da cultura. Tradução Myrian Ávila et al. Belo Horizonte: Ed. UFMG, 1998.

BRASIL. SENADO FEDERAL. Lei $n^{\circ}$ 10.040/2020. Estabelece normas educacionais excepcionais a serem adotadas durante o estado de calamidade pública reconhecido pelo Decreto Legislativo n $^{\circ}$ 6, de20 de março de 2020; e altera a Lei no 11.947, de 16 de junho de 2009, 2020.

BRASIL. SENADO FEDERAL. Lei n ${ }^{\circ}$ 9.394/1996. Estabelece as Diretrizes e Bases da Educação Nacional, 1996.

CONTRERAS DOMINGO, José. Enseñanza, Curriculum y Profesorado: introducción crítica a la didáctica. 2. ed. Madrid: Akal, 1994.

D'AMBROSIO, Beatriz S.; LOPES, Celi E. Insubordinação criativa: um convite à reinvenção do educador matemático. Bolema, v. 29, n. 51, p. 1-17, 2015. Disponível em http://www.scielo.br/pdf/bolema/v29n51/1980-4415-bolema-29-51-0001.pdf. Acesso em 16 jan. 2019.

FREIRE, Paulo. Pedagogia da autonomia: saberes necessários à prática educativa. 28. ed. São Paulo: Paz e Terra, 2003.

MATTOS, Sandra M. N.; MATTOS, José R. L. Etnomatemática e prática docente indígena: a cultura como eixo integrador. Hipátia, v. 4, n. 1, p. 102-115, jun. 2019. Disponível em https://ojs.ifsp.edu.br/index.php/hipatia/article/view/1092/809. Acesso em 12 jun. 2019.

MATTOS, Sandra M. N. O sentido da matemática e a matemática do sentido: aproximações com o programa etnomatemática. São Paulo: Livraria da Física, 2020a.

MATTOS, Sandra M. N. Formação de professores de matemática: ecos em Paulo Freire e no Programa Etnomatemática. In: MATTOS, José R. L.; SILVA, Romaro A. (org.). Etnomatemáticas em vários contextos. Macapá: Edifap, 2020b. p. 247-263.

MESSINA, Graciela. Mudança e inovação educacional: notas para reflexão. Cadernos de Pesquisa, n. 114, p. 225-233, nov. 2001. Disponível em https://www.scielo.br/pdf/cp/n114/a10n114.pdf. Acesso em 16 out. 2020.

MORAN, José. Educação híbrida: um conceito-chave para a educação. In: BACICH, Lilian; Tanzi Neto, Adolfo; TREVISANI, F. M. (org.). Ensino bibrido: personalização e tecnologia na educação. Porto Alegre: Penso, 2013. p. 28-45.

MOTIN, Mara F.; et al. O ensino remoto de disciplinas do eixo da matemática em tempos de pandemia. In: PALÚ, Janete; SCHÜTZ, Jenerton A.; MAYER, Leandro. (org.). Desafios da educação em tempos de pandemia. Cruz Alta: Ilustração, 2020. p. 247-260. 
SANTOS, Boaventura de S.; MENESES, Maria Paula. Introdução. In: SANTOS, Boaventura de S.; MENESES, Maria Paula. (org.). Epistemologias do sul. Coimbra: Almedina, 2009, p. 9-19.

VALENTE, José A. Blended learning e as mudanças no ensino superior: a proposta da sala de aula invertida. Educar em Revista, Edição Especial, n. 4, p. 79-97, 2014. Disponível em https://www.scielo.br/pdf/er/nspe4/0101-4358-er-esp-04-00079.pdf. Acesso em 16 out. 2020.

WALSH, Catherine. Gritos, grietas y siembras de vida: Entretejeres de lo pedagógico y lo decolonial. In: WALSH, Catherine. (ed.). Pedagogías decoloniales: prácticas insurgentes de resistir, (re)existir y (re)vivir. Tomo II. Quito: Abya-Yala, 2017. p. 17-45.

WALSH, Catherine. Introdução. Lo pedagógico y lo decolonial: Entretejiendo caminos. In: WALSH, Catherine. (ed.). Pedagogías decoloniales: prácticas insurgentes de resistir, (re)existir y (re)vivir. Tomo I. Quito: Abya-Yala, 2013. p. 23-68.

Submetido em outubro de 2020 Aprovado em marco de 2021

\section{Informações do(a)(s) autor(a)(es)}

Sandra Maria Nascimento de Mattos

Universidade Aberta do Brasil - UAB/IFAP

E-mail:smnmattos@gmail.com

ORCID: https://orcid.org/0000-0003-2622-0506

Link Lattes: http://lattes.cnpq.br/9632990540395574

José Roberto Linhares de Mattos

Universidade Federal Fluminense - UFF

E-mail: jrlinhares@gmail.com

ORCID: https://orcid.org/0000-0002-4075-6764

Link Lattes: http:// lattes.cnpq.br/1508772914490157 